\title{
DEUTERIUM AS A TOOL FOR CHANGING THE PROPERTIES OF PHARMACEUTICAL SUBSTANCES (REVIEW)
}

\section{ANTON V. SYROESHKIN ${ }^{1}$, TATYANA V. PLETENEVA ${ }^{1}$, ELENA V. USPENSKAYA ${ }^{1}$, OLGA V. LEVITSKAYA ${ }^{1}$, IRINA V. TARABRINA ${ }^{1}$, SVITLANA N. NOVIKOVA ${ }^{2}$, IGOR A. ZLATSKIY ${ }^{2}$}

${ }^{1}$ Peoples Friendship University of Russia (RUDN University), 6 Miklukho-Maklaya St, Moscow, 117198, Russian Federation, ${ }^{2}$ State Institute of Genetic and Regenerative Medicine NAMS of Ukraine, 67 Vyshgorodska Str., Kyiv 04114, Ukraine

*Email: zlatskiy@ukr.net

Received: 16 Apr 2021, Revised and Accepted: 25 May 2021

\section{ABSTRACT}

The review is devoted to the influence of the hydrogen isotope-deuterium on biological models of organisms and the biological activity of pharmaceutical substances.

The positions of the influence of deuterium on the properties of active pharmaceutical ingredients and excipients are examined from different perspectives. The first position reflects an increase in the kinetic isotope effect (KIE) in processes involving known pharmaceutical substances in aqueous solutions with a deuterium/protium ratio $(\mathrm{D} / \mathrm{H})$ below natural. For the first time, the dose-response diagram shows the identity of deuterium with essential trace elements, when a deficiency and excess of an element reduces the organism's vitality. Improved kinetic characteristics are demonstrated for the molecular and organism levels of different hierarchical gradations. In particular, they consist in the possibility of increasing the dissolution rate of substances by influencing the carbohydrate mutarotation processes and the optical activity of chiral substances, increased accumulation of essential elements in medicinal plants and other processes associated with a possible change in metabolic pathways in the cell and the organism as a whole.

The second considered position of the influence of deuterium is associated with the use of deuterated substances-new compounds or obtained by substitution of protium in known protium analogues. The KIE is presented, which is expressed in a decrease in the biotransformation rate as a result of deuteration, it allows predicting a rapid development of the new direction in the development of drugs. Having an identical therapeutic effect, deuterated analogs provide improved pharmacokinetic characteristics, such as reduced toxicity, blocked epimerization of optically active substances, and a change in the mechanisms of biotransformation. The obtained results make it possible to predict the mechanisms of the effect of deuterium on the biochemical transformations of pharmaceutical substances in the organism.

Keywords: Deuterated pharmaceutical substances, Deuterium depleted water, Kinetic isotope effect of deuterium

(C) 2021 The Authors. Published by Innovare Academic Sciences Pvt Ltd. This is an open access article under the CC BY license (https://creativecommons.org/licenses/by/4.0/) DOI: https://dx.doi.org/10.22159/ijap.2021v13i4.41818. Journal homepage: https://innovareacademics.in/journals/index.php/ijap

\section{INTRODUCTION}

The atom of the most common hydrogen isotope, protium ${ }^{1} \mathrm{H}$, has one proton and one electron. Deuterium D $\left({ }^{2} \mathrm{H}\right)$ is a heavier natural isotope of hydrogen with the atomic mass equal to 2 and, unlike protium, it has one neutron in the atomic nucleus [1].

Deuterium is a non-radioactive stable hydrogen isotope that is constantly present in natural water $(\mathrm{D} / \mathrm{H}=140 \pm 5 \mathrm{ppm}$, moderate latitudes of the globe) and in the human body (in amounts comparable to the contents of such essential trace elements as zinc, copper, iron) [2, 3].

Deuterium is used in the nuclear power industry as a neutron moderator in reactors, as well as a stable indicator in chemical and biological models and studies of the mechanisms of various processes [4]. Deuterated compounds, which are identical in size and structure, are obtained by replacing protium with deuterium in the molecule. Due to the higher strength of carbon-deuterium (C-D) chemical bonds vs carbon-protium $(\mathrm{C}-\mathrm{H})$, the properties of deuterated compounds change, for example, the reaction rates with their participation are lower [5].

The first patents for deuterated substances were issued in the United States in the middle of the last century [6]. The research and development task was to obtain substances with lower rates of biotransformation. This allowed reducing doses and minimizing the side effects of drugs.

Considerable experimental material about the effect of the deuterium/protium ratio $(\mathrm{D} / \mathrm{H})$ in water on processes involving biologically active substances in vitro and in vivo has been accumulated [7-16]. It was found that in the range of deuterium content from 0.6 to $16 \mathrm{mmol} / \mathrm{l}$ in deuterium-depleted water (ddw), the kinetic isotope effect (KIE) of biologically active compounds increases [8, 17]. In such water, the rates of dissolution of substances [18] and mutarotation of carbohydrates [19], the optical properties of chiral compounds $[12,17]$ change, the absorption and accumulation of ions of essential trace elements in medicinal and food plants increase [20]. It was proven that obesity in laboratory animals decreases when using ddw water [21]. The use of ddw in oncology as an adjuvant is accompanied by an improvement in the condition of patients $[15,16]$.

The purpose of this review is to summarize information on the effect of the deuterium/protium ratio on living model objects of different hierarchical levels using these data for the analysis of pharmaceutical substances and aqueous solutions with a modified isotopic composition of $\mathrm{D} / \mathrm{H}$ (fig. 1).

Mechanisms of pharmaceutical substance transformation at modified $d / h$ ratio in water

The kinetic isotope effects of deuterium were found in studies of solutions of pharmaceutical substances with different $\mathrm{D} / \mathrm{H}$ ratios. In connection with the use of heavy water $\mathrm{D}_{2} \mathrm{O}$ in the nuclear power industry, the mechanisms of its influence on biological objects were studied in sufficient detail $[22,23]$. However, the behavior of pharmaceutical substances in deuterium-depleted water, as well as the influence of the deuterium/protium ratio on organisms of different hierarchical levels, remained virtually unstudied until the last decade. The research in this direction uses water with a deuterium concentration from $0.5 \mathrm{mmol}$ (D/H ratio of about $5 \mathrm{ppm}$ ) to $16 \mathrm{mmol}$ (which corresponds to the $\mathrm{D} / \mathrm{H}$ ratio of water in the temperate latitudes of the globe-about $140 \mathrm{ppm}$ ). Various processes (dissolution of pharmaceutical substances, mutarotation of glucose and galactose, activation energies of cell transitions of biosensors, 
etc.) illustrated an unexpected increase in rates vs the well-known effects of the complete substitution of deuterium in water [24-32].

Many published data on the properties and biological effects of water depleted in the heavy hydrogen isotope ("light" water, deuterium-depleted water, ddw) show that ddw water is a poorly studied solvent $[8,14,17]$. The definition of "light" water is due to the fact that, as a result of rectification, the proportion of the lightest ${ }^{1} \mathrm{H}_{2}{ }^{16} \mathrm{O}$ isotopologue increases in comparison with world standards $[4,14]$ (table 1).

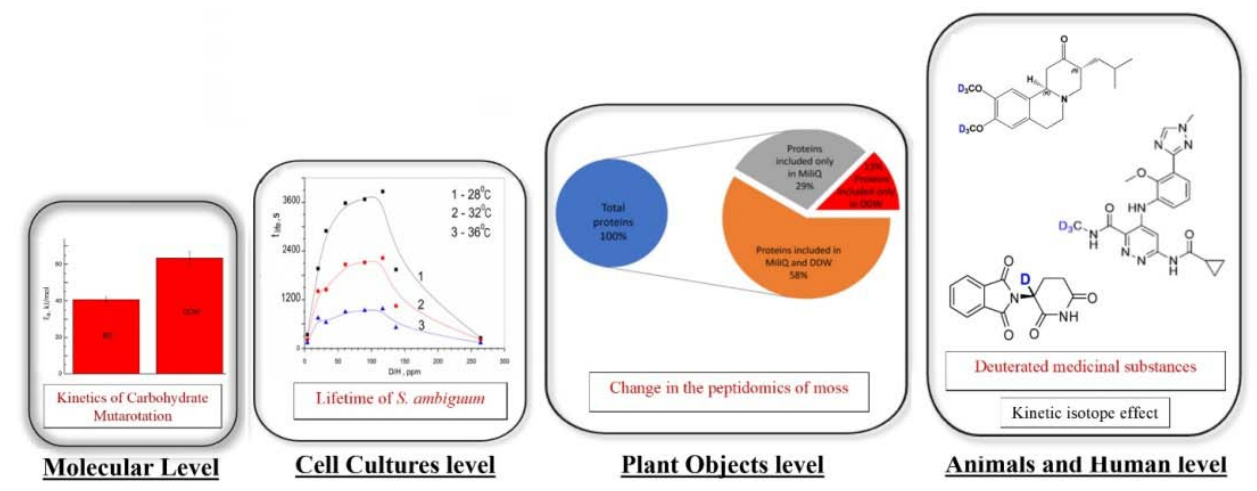

Fig. 1: Diagram of the information presented in the review

Table 1: Major world isotope water standards

\begin{tabular}{|c|c|c|c|c|c|}
\hline Water standard & $\delta \mathrm{D}, \%$ & $\delta^{18} 0, \%$ & D, ppm & 180, ppm & Reference \\
\hline SMOW-V & 0 & 0 & 155.76 & 2005 & {$[4,14]$} \\
\hline Vienna Standard Mean Ocean Water & & & & & \\
\hline $\begin{array}{l}\text { SLAP } \\
\text { Standard Light Antarctic Precipitation }\end{array}$ & -428 & -55.5 & 89 & 1894 & {$[4,14]$} \\
\hline $\begin{array}{l}\text { GISP } \\
\text { Greenland Ice Sheet Program }\end{array}$ & -189.8 & -24.85 & 126.2 & 1955.37 & {$[4,14]$} \\
\hline
\end{tabular}

Acceleration of physicochemical and biological metabolic processes in ddw water leads to various physiological effects: immunostimulating, reproductive, changes in the sensitivity of receptors to endogenous and exogenous ligands, etc. Based on the results of experimental studies, such significant biological responses of ddw are based on differences in the physico-chemical properties of water depleted in the heavy isotope, $\mathrm{D}_{2} \mathrm{O}$ and water of natural isotopic composition (table 2) [8, 14, 17].

Experimental measurements indicate the importance of the H(D) content for measuring the physical constants and properties of the resulting solutions.

Table 2: Physical properties of water with different heavy isotope contents $/\left(\mathrm{T}=20,00 \pm 0,04{ }^{\circ} \mathrm{C}\right)$

\begin{tabular}{|c|c|c|c|c|c|}
\hline No. & Physico-chemical parameter & $\begin{array}{l}\text { DDW water } \\
\text { D/H= 4 } \pm 0.9 \text { ppm }\end{array}$ & $\begin{array}{l}\text { High-resistance water of natural isotopic } \\
\text { composition } D / H=140 \pm 0.9 \mathrm{ppm}\end{array}$ & $\begin{array}{l}\mathrm{D}_{2} \mathrm{O} \\
99.9 \%\end{array}$ & Reference \\
\hline 1 & Surface Tension $\sigma, \mathrm{mN} / \mathrm{m}$ & 75.172 & 72.860 & 67.800 & [14] \\
\hline 2 & Kinematic Viscosity, $\mathrm{mm}^{2} / \mathrm{s}$ & 0.987 & 1.012 & 1.274 & [14] \\
\hline 3 & $\begin{array}{l}\text { Density }{ }^{*}, \mathrm{~g} / \mathrm{cm}^{3} \\
* 0[18] / O[16]=757 \mathrm{ppm}^{*} t^{o}=25 \pm 0.05{ }^{\circ} \mathrm{C}\end{array}$ & 0.9969 & 0.9982 & 1.1042 & {$[14]$} \\
\hline 4 & Freezing Point, $\mathrm{T}^{\circ} \mathrm{C}$ & -1.5 & 0 & $+3,8$ & [14] \\
\hline 5 & $D_{l}$-self-diffusion coefficient, $\cdot 10^{9}, \mathrm{~m}^{2} \mathrm{~s}^{-1}$ & 0.63 & 0.46 & 0.52 & [14] \\
\hline 6 & $\begin{array}{l}\text { Spin-spin Relaxation Time of the Water } \\
\text { Proton } t, s\end{array}$ & 0.347 & 2.000 & - & {$[14]$} \\
\hline 7 & $\begin{array}{l}\text { Volume concentration * of density } \\
\text { inhomogeneities, vc (\%) } \\
{ }^{*} \text { according to the LALLS method data }\end{array}$ & 0.20 & 1.00 & 0.18 & {$[14,17]$} \\
\hline 8 & $\begin{array}{l}\text { Obscuration* due to laser light scattering, } \\
\text { laserobscuration }(\lambda=633 \mathrm{~nm}) \\
\text { *according to the LALLS method data }\end{array}$ & 0.003 & 0.020 & 0.005 & {$[14,17]$} \\
\hline
\end{tabular}

\section{Isotopic effect at the molecular level}

\section{Kinetics of Carbohydrate Mutarotation}

Differences in the kinetics of carbohydrate mutarotation were found (fig. 2). They can be associated with differences in the lengths and energies of $\mathrm{O}-\mathrm{H}$ and $\mathrm{O}-\mathrm{D}$ bonds of water, which is involved in establishing equilibrium between carbohydrate anomers through an acyclic form. This is confirmed by the significantly lower mutarotation rate of both galactose enantiomers in deuterated water (fig. 2) [19, 23]. In natural and ddw water, these rates are significantly lower for the L-form of the optical isomer. In $\mathrm{D}_{2} \mathrm{O}$ water, the mutarotation of the L-isomer does not occur at all.

The influence of the isotopic composition of water was confirmed by studying the temperature dependence of the kinetics of D-glucose mutarotation in Arrhenius coordinates. The activation energy (Ea) of the mutarotation process in natural high-resistance water is $\mathrm{Ea}=$ $40.8 \pm 1.4 \mathrm{~kJ} / \mathrm{mol}$, whereas in $\mathrm{ddw} \mathrm{Ea}=63.6 \pm 3.5 \mathrm{~kJ} / \mathrm{mol}$, i.e. the kinetic isotope effect estimated through the activation energy is greater than one and amounts to 1.6 (fig. 3.). This also indicates the isotopic dependence of the process. 

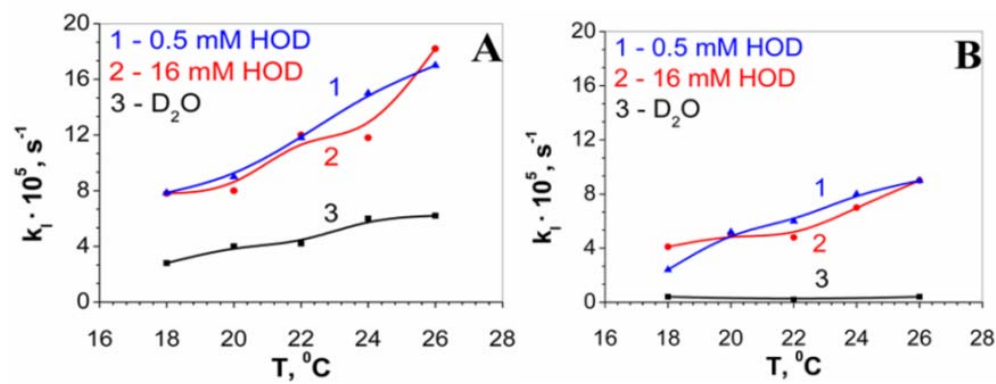

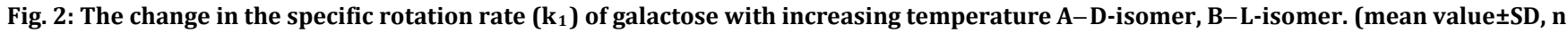
$=6, p<0.05)[7]$

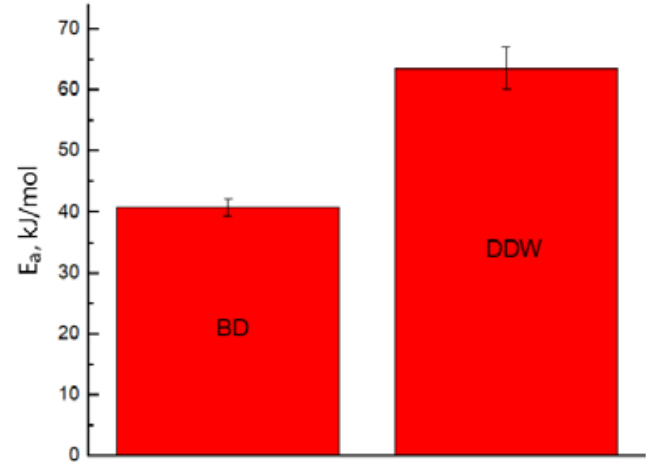

Fig. 3: The energies activation (Ea) of the D-glucose mutarotation in waters with different deuterium contents. [D]/[H]: BD-140 ppm, DDW-4 ppm [19]
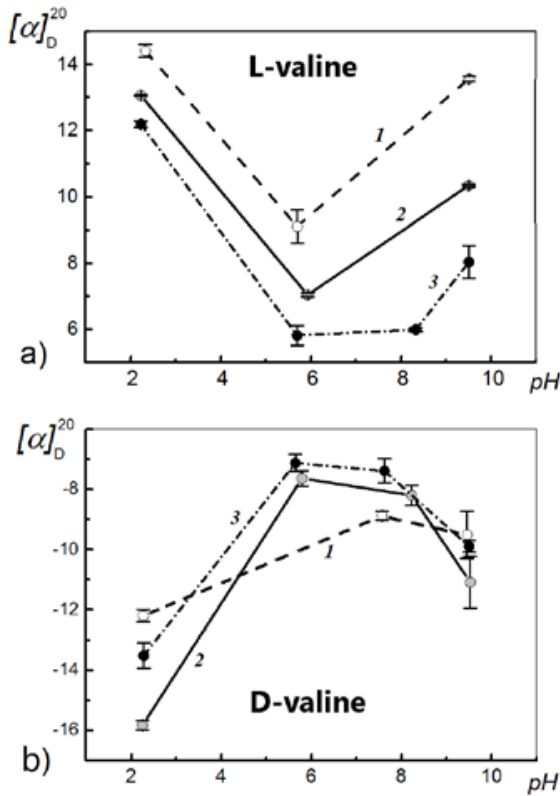

Fig. 4: Dependence of the specific rotation of valine on the $\mathrm{pH}$ of aqueous solutions with different ratios of $\mathrm{D} / \mathrm{H} .1-\mathrm{D} / \mathrm{H}=4 \mathrm{ppm}$; 2-D/H = 140 ppm; 3-99.9\% $\mathrm{D}_{2} \mathrm{O}$ [13]

\section{Optical rotation of amino acids}

There were found statistically significant differences in specific rotation of optical valine isomers in waters of different isotopic compositions (fig. 4) [12, 17, 33]. There is a clear dependence of the optical activity on the deuterium content in water within the range of $\mathrm{pH}=2-10$. Uncompensated positive or negative charge in a solution of two optical antipodes was detected. This is explained by the formation of chirality in giant heterogeneous water clusters (GHWC) under the influence of an optically active amino acid [12].

The obtained results make it possible to consider waters with different deuterium contents as liquids that differ by heterogeneity in addition to their physical properties. The contribution of the anisotropic medium to the manifestation of the optical activity of chiral compounds can be explained by the formation of supramolecular structures of GHWC, the formation of which critically depends on the deuterium content $[8,14,17]$. The phenomenon of homochirality of biologically active substances (for example, natural proteins consist only of L-amino acids, while Damino acids are part of cell membranes) may be associated with the isotopic composition and other physico-chemical parameters of the solvent (water) in which biosystems were formed.

\section{The dissolution rate of pharmaceutical substances}

The dissolution kinetics of a large number of pharmaceutical substances controlled by laser obscuration demonstrated an increase in KIE with a decrease in the $\mathrm{D} / \mathrm{H}$ ratio in water (table 3) [18].

Comparison of KIE-deuterium of various pharmaceutical substances demonstrates the dependence on the isotopic composition of the solution.

Table 3: Kinetic isotope effects of lactose monohydrate calculated by the rate $(k)$ of dissolution of the substance in aqueous solutions with different $\mathrm{D} / \mathrm{H}$ ratios [18]

\begin{tabular}{lllll}
\hline & $\frac{\boldsymbol{k}_{\text {DDW }}}{\boldsymbol{k}_{\text {MilliQ }}}$ & $\frac{\boldsymbol{k}_{\text {DDW }}}{\boldsymbol{k}_{\text {D2O }}}$ & & $\frac{\boldsymbol{k}_{\text {MilliQ }}}{\boldsymbol{k}_{\text {D2O }}}$ \\
\hline 1,7 & 2,6 & 1,5 \\
\hline
\end{tabular}

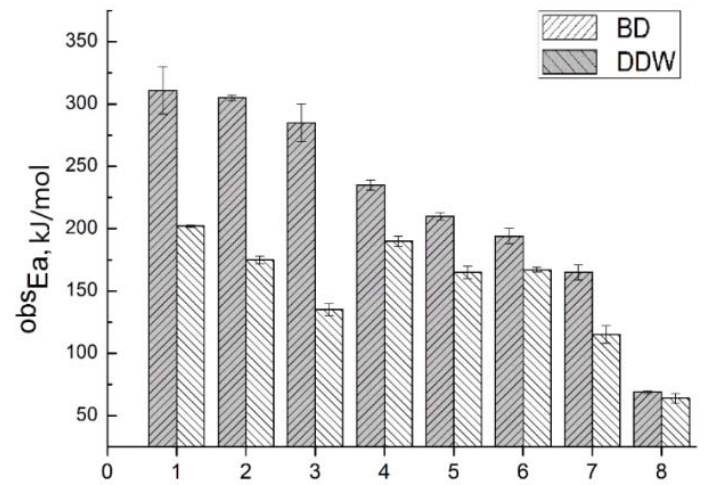

Fig. 5: Xenobiotic ranking by values ${ }^{\mathrm{obs}} \mathrm{E}_{\mathrm{a}}$ in deuterium-depleted water-DDW $(\mathrm{D} / \mathrm{H}=4 \mathrm{ppm})$ and high-resistance water of natural isotopic composition-BD $(D / H=140 \mathrm{ppm}): t_{\text {life }}=300$ sec, $\mathrm{T}=28^{\circ} \mathrm{C} ; 1$ 1- $\mathrm{Na}_{2} \mathrm{SO}_{3}, 2$-3-hydroxy-6-methyl-2-ethylpyridine succinate (mexidol), 3-ascorbic acid, 4- $\mathrm{Na}_{2} \mathrm{H}_{2}$ EDTA, 5-3-

hydroxy-6-methyl-2-ethylpyridine hydrochloride (emoxypine), $6-\mathrm{ZnSO}_{4} \cdot 7 \mathrm{H}_{2} \mathrm{O}, 7-\mathrm{CuSO}_{4} \cdot 5 \mathrm{H}_{2} \mathrm{O}, 8-\mathrm{NaCl}$ [9] 


\section{Organism level}

\section{Cell cultures}

The survival rate of a unicellular organism, S. ambiguum ciliates, in aqueous solutions of active pharmaceutical ingredients (API) and excipients with different $\mathrm{D} / \mathrm{H}$ ratios was studied in detail [9]. In waters of different isotopic compositions, there were obtained statistically significant differences in the apparent activation energy of obsEa ligandinduced cell death in solutions of a number of substances (fig. 5).

The rate constant of the process of irreversible cell transition of $S$. ambiguum from the active to immobilized state decreases by more than an order of magnitude when deuterium is depleted from 16 $\mathrm{mmol}$ to $0.5 \mathrm{mmol}$. The cell biosensor lifetime curve runs almost
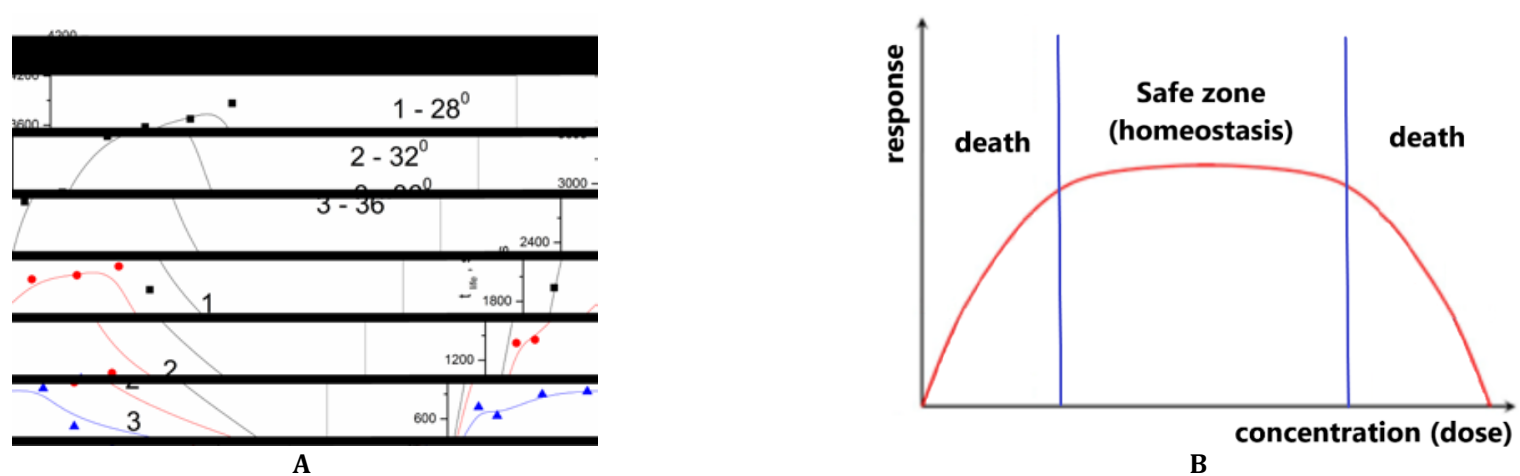

Fig. 6: The dependence of the lifetime of $S$. ambiguum on the concentration of deuterium in water at 28 (1), 32 (2) and $36^{\circ} \mathrm{C}(3)-\mathrm{A}$ (Results are expressed as a mean value \pm standard deviation $(n=18), p<0,01)[7]$ and the dose-response diagram for essential elements-B
A change in the proliferation rate depending on the concentration of deuterium in the culture medium was shown on in vitro culture of human adipose-derived stromal cells (ADSCs) [33-35]. Morphological changes in the deuterated medium were observed: the cells did not reach confluence, they had a polygonal morphology with pronounced stress febrile. At high deuterium contents in the nutrient medium, an increase in the doubling time for the population was noted, which indicates a slowdown in the cell cycle and, as a consequence, the proliferative ability of the cell culture. The lowest migration rate was observed in the deuterated nutrient medium, and the most active migration ability was observed in the deuterium-depleted medium with a close to in the metabolic activity is observed on the third day, and in the deuterium-depleted medium, an increase in the viability of the ADSCs culture is noted. The differentiation of ADSCs into adipocytes was also carried out under the conditions of different deuterium contents in the nutrient medium [36]. It was found that a high $\left(5 \cdot 10^{5} \mathrm{ppm}\right)$ deuterium content significantly inhibited in vitro the adipogenic differentiation of human ADSCs compared to groups with natural $(150 \mathrm{ppm})$ and low $(30 \mathrm{ppm})$ deuterium content. It is important that the differentiation protocol used in the study led to the development of white adipocytes in groups with natural (control) and high deuterium content, while the deuterium-depleted differentiation medium led to the formation of brown-like (beige) adipocytes. This is important from the point of view of the energy component of the cell and the organism as a whole $[25,26]$. The inhibitory effect of deuterium on metabolic activity and a subsequent decrease in the effectiveness of the adipogenic differentiation is probably associated with mitochondrial dysfunction. These data can serve as the basis for the development of new approaches to the treatment of obesity, metabolic syndrome and diabetes through the regulation of stem cell differentiation and adipocyte functions.

Thus, deuterium was considered as an element that affects the chirality of a substance in biological models in vitro/in vivo $[4,7,15$, $27,36]$. natural $\mathrm{D} / \mathrm{H}$ ratio. In the deuterated nutrient medium, a decrease parallel to the axis of abscissas within the interval of $\mathrm{D} / \mathrm{H}$ values from $90 \mathrm{ppm}$ to $150 \mathrm{ppm}$ and gradually decreases beyond this interval (fig. 6).

The "dose-response" relationship for the $\mathrm{D} / \mathrm{H}$ ratio is identical to the classical curves for essential trace elements: their deficiency or excess leads to the death of the animal. At the same time, there is a safety zone that ensures the normal survival of the organism [12, 23]. It turned out that water with a low deuterium content exhibited antidote properties: a decrease in the content of the heavy hydrogen isotope led to an increase in the survival of ciliates by one and a half times on average. As in the previous examples, KIE-deuterium calculated for numerous substances through the activation energies of cell death exceeded one.

\section{Plant objects}

For the basket plant (Callisia fragrans L.), it was found that the redistribution and assimilation of mineral components goes fastertwo or more times-in deuterium-depleted water compared to water with natural isotopic composition. This allowed using Callisia as a model object of saturation with microelements, in particular, zinc $[20,37]$.

As is known, Physcomitrella Patens moss is an important fundamental object of proteomics. In the study of moss of this species, a significant difference in the peptide composition in waters with different D/H ratios was found (fig. 7) [37]. It should be noted that the sprouting of moss was carried out by hydroponics, i.e. the intake of water and all nutrient substances in the model was direct to the plant organism without the participation of intermediate elements or other routes of administration as it is presented in some animal or cell culture models.

The diagram shows that moss sprouted on deuterium-depleted water has a unique peptidomics, where $13 \%$ of the proteins are found only in this experimental group. In addition, it was found that $29 \%$ of the proteins were not found in the composition of the moss sprouted on DDW vs water with the natural isotopic composition. This dependence can be associated with a change in the metabolism of the organism and deuterium can be considered as an element that affects the chirality of the substance $[7,17]$. In other words, the presence of deuterium or protium in a biological substance can be represented as a "switch on/off" mechanism, which leads to different ways of further reactions and, respectively, the entire metabolism can go in different directions (at different rates) depending on the presence of deuterium or protium in the original or intermediate substance $[7,38]$. It is worth noting that a similar isotopic dependence is known in nature for other isotopes, such as carbon and magnesium. So, the differences between monocotyledonous and dicotyledonous plants are determined by the ratio of carbon isotopes $\left(\mathrm{C}_{12}, \mathrm{C}_{13}\right)$ [39]. In turn, the $\mathrm{Mg}_{24}, \mathrm{Mg}_{25}$ isotopes have their own specifics of kinetic interactions and differently participate in metabolic processes [40]. 


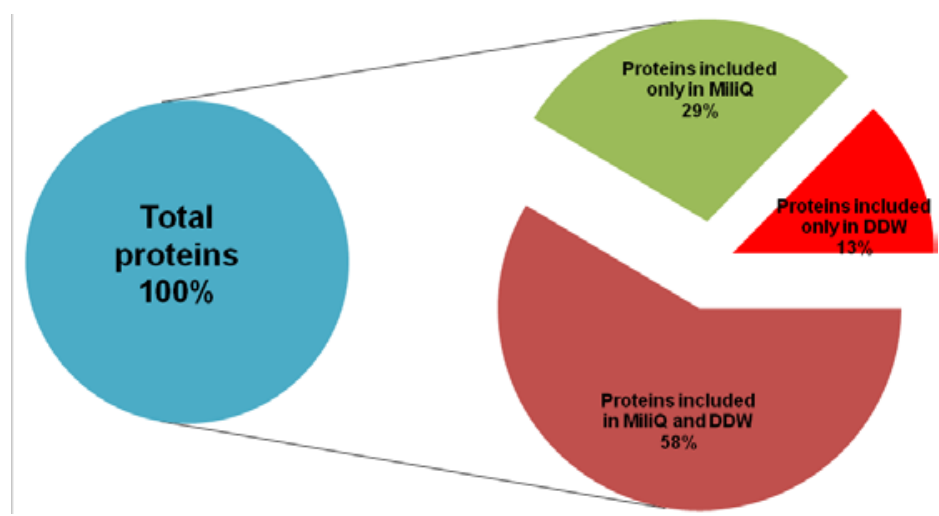

Fig. 7: Change in the peptidomics of moss sprouted on the water with different $D / H$ isotope ratios

\section{Animals and Human}

The deuterium content in the body of a "conditional" human (weighing $70 \mathrm{~kg}$ ) is about $1 \mathrm{~g}$, which corresponds to its position between copper (100 mg) and zinc ( $2 \mathrm{~g}$ ) and is 2-3 orders of magnitude higher than Co, Mn, Mo when ranking the essential trace elements [41]. This allows predicting its key role in biochemical processes in the body. In contrast, when drinking water is replaced by ddw, the deuterium content in aqueous extracts of biological samples of blood, muscle tissue and liver tissue of laboratory animals decreases [42]. Many experimental results obtained in vitro and in vivo in Hungary, Japan, USA, China, Romania, Russia suggest the possibility of using ddw as an adjuvant in the treatment of various diseases [28-31], including cancers [43-45]. The replacement of natural water $(\mathrm{D} / \mathrm{H}=132-156 \mathrm{ppm})$ with $\mathrm{ddw}(\mathrm{D} / \mathrm{H}$ $=20-120 \mathrm{ppm}$ ) is accompanied by a decrease in tumor size, gradual necrosis of tumor cells, an increase in the average survival of patients (prostate cancer, breast cancer, lung cancer and others) [1, $14,54]$. Based on the study by G. Somlay, in Hungary since 1990, there has been existing hope for the possibility of treating or reducing the effects of cancers in the 21 st century $[2,15,16,38,46]$.

Thus, studies carried out on various biologically active substances and in vitro/in vivo model biological objects, including humans, have shown the effectiveness of using deuterium as a tool to change the rate of chemical reactions and metabolism in general. This is an important mechanism in the fight against complications in the treatment and prevention of various diseases. The method of regulating biological activity using deuterium is confirmed by studies of deuterated medicinal substances, which are discussed in the next section.

\section{Deuterated medicinal substances}

Differences between deuterium and protium from the standpoint of pharmaceutical chemistry

Compared with protium $(\mathrm{H})$, deuterium (D) is more resistant to oxidation. The C-D bond length is shorter by $0.005 \AA$ compared to C-H. Since the D atom has a 2 times larger mass than $H$, the activation energy required to achieve the transition state at bond breaking is greater for $\mathrm{C}-\mathrm{D}$ than for $\mathrm{C}-\mathrm{H}$. That is why the rate of the reaction involving the deuterated compound is lower than for its protium analogue $\left(\mathrm{k}_{\mathrm{H}}>\mathrm{k}_{\mathrm{D}}\right)$. The KIE expressed as the ratio of the reaction rate constants of the protium and deuterated compounds $\mathrm{k}_{\mathrm{H}} / \mathrm{k}_{\mathrm{D}}$ is normally ranges from 1 to 7 but may be higher [6]. Replacing protium with deuterium is an example of isosteric substitution. The pairs of pharmaceutical substances, the original/parent protium-containing and its deuterated analogues are called "bioisosteres". Deuteriummodified bioisosteres are characterized by the invariability of biological activity and the optimization of pharmacokinetics.

Two basic approaches can be used in the synthesis of deuteriumlabeled compounds. This is a common multi-step synthesis, the socalled "deuterated pool synthesis", using deuterated reagents. The second approach, which is used more often, is the deuteration of the parent compound by the H/D isotope exchange method [5]. In some cases, it is convenient to combine both approaches. The introduction of deuterium into the target molecule or into the intermediate substance at the late stage of synthesis is carried out using deuterium donors-usually $\mathrm{D}_{2} \mathrm{O}$ or deuterium gas, $\mathrm{D}_{2}$. The isotope protium-deuterium exchange (H/D) depends on $\mathrm{pH}$ [47] and the nature of the catalyst $[1,48]$.

The nomenclature of deuterated compounds is simple. Typically, the derivative compound has a prefix deu-followed by the identical name for the precursor compound (eg, deuterotrabenazine). For brevity, the prefix deu-is replaced by di-, where $i$ is the number of deuterium atoms in the molecule. Lists of all WHO-approved compound names and structures are published in WHO documents. Currently, the list includes deutolperisone, deutetrabenazine, deudextromethorphan, deuivacaftor and is supplemented with the names of new deuterated substances.

\section{History of deuterated pharmaceutical compounds}

The very first examples of deuterium inclusion in biologically active compounds are mentioned in the works of the mid-20th century. Two independent research groups reported a decrease in the biotransformation rate of $\mathrm{d}_{2}$-tyramine and $\mathrm{d}_{3}$-morphine compared to the parent proton-containing compounds $[49,50,51]$. The time interval between the publication of the first patents for a deuterated substance and the registration of drugs based on them was about half a century. Such an example is deutetrabenazine $\left(d_{6}\right.$ tetrabenazine) approved by the Food and Drug Administration (FDA) in 2017 (table 4). Its protium precursor tetrabenazine was registered in the USA in 2008. Since 2018, the drug (trade name Normokineztin) has been included in the list of vital and essential drugs in the Russian Federation. Chemically, deutetrabenazine is an isotopic isomer of tetrabenazine ("bioisostere"), in which six protium atoms are replaced by deuterium atoms. An increase in the half-life of the deuterated drug from the bloodstream from 4.8 to 8.6 $\mathrm{h}$ and an approximately twofold increase in the area under the pharmacokinetic curve (AUC) allowed halving the dose vs tetrabenazine. Thus, the new drug is characterized by a reduced number of daily injections, and its tolerance is improved compared to the parent compound [52]. Indications for the use of the drug are the same as for tetrabenazine, therefore, when registering deutetrabenazine, the applicant was given the right to partially use the registration materials of the parent drug.

The first registration of a deuterated drug is a significant event for a new direction of pharmacy [5].

Another deuterated drug, a combination of $\mathrm{d}_{6}$-dextromethorphan and quinidine (table 4), has been supported by FDA for accelerated promotion but has not yet reached final regulatory approval [53]. Its ancestor-the combined drug Nuedexta ${ }^{\circledR}$ consisting of $20 \mathrm{mg}$ of dextromethorphan and $10 \mathrm{mg}$ of quinidine-is used to treat pseudobulbar affect. Quinidine slows the metabolism of dextromethorphan to an O-demethylated product in the first stage of biotransformation and increases the half-life. This allowed achieving therapeutic values for the content of the active ingredient within the 
safety interval. It turned out that achieving equivalent effects with deuterated dextromethorphan requires the significantly lower quantity of toxic quinidine. Increase in $t_{1 / 2}$ of $d_{6}$-dextromethorphan allowed not only reducing the dose of the active pharmaceutical substance, but also providing protection against the side effect of quinidine. Due to the fact that there is currently no FDA-approved drug for the treatment of dementia, although the need for such a drug is significant, the opportunity was provided to expedite the registration of the deuterated drug. The studies are in Phase III of clinical trials for the treatment of delirium associated with Alzheimer's disease. In addition, Phase II of these clinical trials continues in the treatment of resistant depression and residual schizophrenia.

Table 4: Advantages of deuterated drugs

\begin{tabular}{lll}
\hline Deuterated analogue & $\begin{array}{l}\text { Pharmacokinetic characteristics, mechanisms } \\
\text { of biotransformation }\end{array}$ & Use \\
\hline & $\begin{array}{l}\text { Increase in } \mathrm{t}_{1 / 2} \\
\text { from } 4.8 \text { to } 8.6 \mathrm{~h}\end{array}$ & $\begin{array}{l}\text { Designed to reduce symptoms of an } \\
\text { orphan disease-Huntington's chorea }\end{array}$ \\
Twofold AUC Increase & \\
& &
\end{tabular}

$\mathrm{d}_{6}$-Tetrabenazine

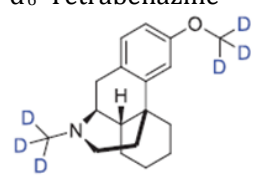

Increase in $\mathrm{t}_{1 / 2}$, AUC and Cmax

Ultra-low dose of quinidine compared to the protium precursor

$\mathrm{d}_{6}$-Dextromethorphan + Quinidine<smiles>COc1c(Nc2cc(NC(=O)C3CC3)nnc2C(=O)NC(=O)OCc2ccccc2)cccc1-c1ncn(C)n1</smiles>

Tyrosine kinase inhibitor

DNA-dependent protein kinase inhibitor

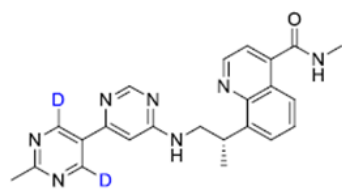

VX-984<smiles>[2H]C([2H])(N)C([2H])(N)c1ccc(O)c(O)c1</smiles>

$\mathrm{d}_{3}$-Levodopa

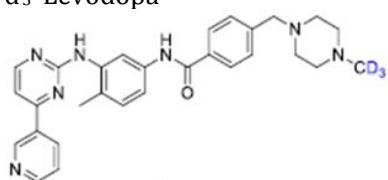

$\mathrm{d}_{3}$-Imatinib

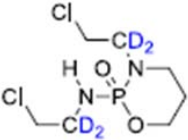

Increased therapeutic index due to the predominance of hydroxylation over $\mathrm{N}$ dechlorination

Change in the rate of reactions catalyzed by monoamine oxidase (MAO) and dopamine $\beta$ hydroxylase $(\mathrm{DBH})$

Decreased N-demethylation during incubation with human liver microsomes.

R-enantiomer is

5 times more stable to epimerization compared to the protium analog
$\mathrm{d}_{4}$-Ifosfamide

S-and R-enantiomers of Thalidomide
For the treatment of pseudobulbar affect; phase III of clinical trialsdelirium associated with Alzheimer's disease; phase II-depression and residual schizophrenia.

A new substance with no protium analogue.

Preclinical trials-

systemic lupus erythematosus and inflammatory bowel disease

A new substance with no protium analogue.

Clinical trials-treatment of psoriasis metastatic endometrial cancer

Parkinson's disease

An anti-leukemic cytostatic drug targeted cytostatic selectively affecting cells with certain genetic defects characteristic of tumors

A cytostatic antitumor chemotherapeutic drug with an alkylating effect.

Immunomodulators.

$\mathrm{S}(+)$-deuterated enantiomer is an antitumor drug, while R(-)-deuterated enantiomer has almost no effect on tumor growth. treatment of psoriasis [55]. Being an inhibitor of DNA-dependent protein kinase, it also successfully passed the first phase of clinical trials in the treatment of metastatic endometrial cancer [56]

Most studies of deuterated drugs are devoted to their pharmacokinetic profiles, which are compared with the parent drugs. As a rule, the deuteration leads to an increase in $\mathrm{C}_{\max }, \mathrm{t}_{1 / 2}$, AUC
There are known deuterated bioactive compounds that are not analogues of known drugs. Among the substances of this group, two trials (see table 4). The first compound is a potent selective tyrosine kinase inhibitor. Its effectiveness has been demonstrated in a number of preclinical models [54]. For the second compound, VX-984, there were obtained promising results of a placebo-controlled clinical trial in the 
and a decrease in clearance, while the effect on $\mathrm{T}_{\max }$ is less pronounced $[5,6]$.

It is noteworthy that deuterium can also be used not only to prolong the release of drugs but also for the biodegradation of polymer materials in encapsulated forms [57].

\section{Biotransformation and deuteration of drugs}

The substitution of protium by deuterium is usually used to reduce the rate of biotransformation of a drug, primarily in oxidative processes involving cytochrome P450 (CYP450). So, when developing the $\mathrm{d}_{3}$-L-DOPA drug, it was found that the deuteration of the parent molecule leads to a change in the rate of reactions catalyzed by monoamine oxidase (MAO) and dopamine $\beta$ hydroxylase (DBH). After the decarboxylation of d3-L-DOPA with the participation of roamatic L-amino acid decarboxylase (AADC), deuterium-dependent biotransformation of $d_{3}$-dopamine is observed [58]. The appearance of deuterium at the $\alpha$-carbon atom reduces the MAO activity and the amount of $d_{2}-3,4$ dihydroxyphenylacetic acid formed. The appearance of deuterium at the $\beta$-carbon atom is accompanied by a decrease in DBH activity and the amount of $\mathrm{d}_{2}$-norepinephrine. When modeling Parkinson's disease in rodents, the deuterated preparation of $\mathrm{d}_{3}$-levodopa was more effective than the protium precursor [58].

Thus, the introduction of deuterium into various centers of the initial molecule can change the rates of individual pathways of biotransformation of deuterated drugs and the accumulation of certain biologically active products.

\section{Toxicity reduction by deuteration}

The deuteration can be used to reduce the number and amount of unwanted metabolites ("metabolic shunting"). The inclusion of deuterium in the $\alpha$-and $\alpha$-positions in ifosfamide leads to an increase in hydroxylation in position 4 (see table 4 ) and a decrease in the toxic products of $\mathrm{N}$-dechlorination for $\mathrm{P} 450$ family enzymes vs the non-deuterated drug [59]. The metabolic shunting expressed in the predominance of hydroxylation over $\mathrm{N}$-dechlorination with the

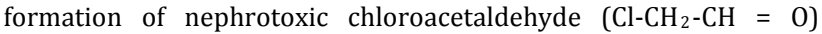
increases the therapeutic index of the drug.

The deuteration of the erythromycin B molecule is also accompanied by a decrease in the side effects of intestinal motility as a result of suppression of the formation of 6,9-enol ether [60]. In this case, the antibacterial effect of the drug is not violated.

The result of the study of tramadol, which is rapidly metabolized to an 0-demethylated metabolite, is interesting [61]. The identical biotransformation product of $\mathrm{d}_{9}$-tramadol shows 5-10 fold activity in relation to opioid receptors in vitro.

\section{Stabilization of stereoisomers at deuteration}

To reduce the side effects of optically active pharmaceutical substances, enantiopure drugs have been developed since 1992. This technologically difficult procedure made it possible to register more effective enantiomers, eutomers, as new drugs [62-64]. This approach, known as "chiral switch", ended in the commercial avaiability of pure enantiomers $[65,66]$.

At the same time, for a number of optically active substances, the chiral switch is impossible due to the rapid interconversion of stereoisomers in vitro and/or in vivo. Replacing protium with deuterium in the chiral center of one of the stereoisomers can stabilize the stereoisomer.

The teratogenic effect of thalidomide (see table 4) relates mainly to the $\mathrm{S}(+)$-enantiomer [67]. The administration of only the $\mathrm{R}(-)$ enantiomer does not prevent the manifestation of teratogenicity due to a significant and rapid epimerization in physiological conditions. It was shown that the deuteration partially overcomes this disadvantage: $\mathrm{d}_{1}$-thalidomide is 5 times more stable to epimerization in various buffer solutions than its protium analogue.

The effect of deuterium on the kinetic effects of biotransformation of pharmaceutical substances is not limited to the examples given.
More and more deuterated compounds are characterized as promising substances for possible use as drugs [68-75].

\section{Prospects for the use of deuterated compounds}

In the wake of the successful registration of deuterotrabenazine, a number of other deuterated compounds are actively participating in clinical trials.

Undoubtedly, the mechanisms of the influence of deuterium in water on the biochemical transformations of pharmaceutical substances in the body will become clear in the near future. One of the possible options for such a decoding can be the example of mutarotation of carbohydrates going through an acyclic form with the participation of water molecules of mixed isotopic composition (H-O-D).

Like any other essential element, deuterium at fairly high concentrations can be toxic. It is believed that the threshold for clinically significant side effects is from 200 to $400 \mathrm{mg} / \mathrm{kg}$ of pure deuterium oxide-heavy water $\mathrm{D}_{2} \mathrm{O}$ (i.e. $14 \mathrm{~g}$ for a person weighing $70 \mathrm{~kg}$ ). This is many times higher than what is provided for the medical use of deuterated drugs. Indeed, the amount of deuterium in bioactive molecules is 2-3 orders of magnitude lower. Thus, the safety of deuterium as such is not a real concern. Another issue that limited the studies of deuterated drugs in the past was the lack of sensitive analytical methods (e. g. LC/MS/MS) to determine the deuterium content in a substance.

The patentability of deuterated compounds is an urgent concern. Deuterated compounds are not the subject of patenting, but a change in metabolic mechanisms when replacing protium with deuterium is a more significant point. In addition, it should be taken into account that, for many years, deuteration was not a common practice and, therefore, outdated technological conditions for the preparation of parent drugs, i.e. protium precursors, cannot be included in patents.

The FDA approval of deuterotrabenazine increases the likelihood that deuteration will receive green light for preclinical and clinical trials of substances. The trend of increasing in the number of substances with improved pharmacokinetic characteristics suggests further successful registration of new deuterated drugs. For comparison, the example with the fluorine atom can be given. In the 1970 s, fluorine was part of less than $2 \%$ of drugs. However, at present, it can be found in $25 \%$ of registered medicines. This is likely to be the fate that awaits deuterium.

\section{CONCLUSION}

While the use of deuterium in drug development is steadily increasing, the number of issues regarding the use of this bioisosteric replacement is not decreasing. Among them, there is an erroneous opinion about the possible toxicity of deuterium, uncertainty regarding the costs of the production of deuterated drugs, unclear mechanisms for increasing KIE for individual substances, a long approval process of deuterated drugs by regulatory authorities. However, taking into account many considerations of the KIE of pharmaceutical substances in waters with different $\mathrm{D} / \mathrm{H}$ ratios, it can be predicted that deuterium becomes a medical and chemical tool.

\section{ACKNOWLEDGEMENT}

This paper has been supported by the RUDN University Strategic Academic Leadership Program.

\section{FUNDING}

Nil

\section{AUTHORS CONTRIBUTIONS}

All the authors have contributed equally.

\section{CONFLICT OF INTERESTS}

The authors declare that there is no conflict of interests.

\section{REFERENCES}

1. Atzrodt J, Derdau V, William J, Reid M. Deuterium-and tritiumlabeled compounds: applications in the life sciences. Angew Chem Int Ed 2018;57:1758-84. 
2. Anton Syroeshkin, Olga Levitskaya, Elena Uspenskaya, Tatiana Pleteneva. Deuterium depleted water as an adjuvant in the treatment of cancer. Sys Rev Pharm 2019;10:112-7.

3. Zoroddu MA, Aaseth J, Crisponi G, Medici S, Peana M, Nurchi VM. The essential metals for humans: a brief overview. J Inorg Biochem 2019;195:120-9.

4. Basov A, Fedulova L, Baryshev M, Dzhimak S. Deuteriumdepleted water influence on the isotope $2 \mathrm{H} / 1 \mathrm{H}$ regulation in body and individual adaptation. Nutr 2019;11:1903.

5. Tracey Pirali, Marta Serafini, Sarah Cargnin, Armando A Genazzani applications of deuterium in medicinal chemistry. J Med Chem 2019;62:5276-97.

6. Roger D Tung. Deuterium medicinal chemistry comes of age. Future Med Chem 2016;8:491-4.

7. Syroeshkin AV, Pleteneva TV, Uspenskaya EV, Zlatskiy IA Antipova NA, Grebennikova TV, et al. D/H control of chemical kinetics in water solutions under low deuterium concentrations. Chem Eng J 2019;377:119827.

8. Goncharuk VV, Syroeshkin AV, Zlatskiy IA, Uspenskaya EV, Orekhova AV, Levitskaya OV, et al. Quasi-chemical description of the kinetics of cell death Spirostomum ambiguum biosensor for the biological activity of aqueous solutions. J Water Chem Techn 2017;39:97-102.

9. Levitskaya OV, Syroeshkin AV, Pleteneva TV. Arrhenius kinetics as a bioactivity assessment criterion for drug substances and excipients. Pharm Chem J 2016;49:779-81.

10. Titorovich OV, Lyulina EB, Pleteneva TV, Maksimova TV, Syroeshkin AV, Uspenskaya EV, et al. Reaction of an antioxidant (Sodium Sulfite) with 3-hydroxy-6-methyl-2-ethylpyridinium salts. Pharm Chem J 2015;48:842-4.

11. Tsisanova ES, Uspenskaya EV, Pleteneva TV, Syroeshkin AV Study of biological activity and $\mathrm{D} / \mathrm{H}$ ratio of water with the aid of cellular biosensor spirostomum ambiguum. Trace Elements Med 2010;11:8

12. Syroeshkin AV, Pleteneva TV, Uspenskaya EV, Levitskaya OV, Tribot-laspiere MA, Zlatsky IA, et al. Polarimetric research of pharmaceutical substances in aqueous solutions with different water isotopologues ratio. Int J Appl Pharm 2018;10:20182.

13. Syroeshkin AV, Pleteneva TV, Uspenskaya EV, Levitskaya OV. Optical methods in studies of the chiral properties of drugs I. Valine in water with various deuterium contents. Vedomosti Sci Center Expertise Med Applications 2016;1:25-9.

14. Goncharuk VV, Lapshin VB, Burdeinaya TN, Pleteneva TV, Chernopyatko AS, Atamanenko ID, et al. Physicochemical properties and biological activity of the water depleted of heavy isotopes. J Water Chem Techn 2011;33:15-25.

15. Somlyai G, Javaheri B, Davari H, Gyongyi Z, Somlyai I, Tamaddon $\mathrm{KA}$, et al. Pre-clinical and clinical data confirm the anticancer effect of deuterium depletion. Biomacromol J 2016;2:1-7.

16. Krempels K, Somlyai I, Gyongyi Z, Ember I, Balog K, Abonyi O, et al. Retrospective study of survival in breast cancer patients undergoing deuterium depletion in addition to conventional therapies. J Cancer Res Ther 2013;1:194-200.

17. Goncharuk VV, Syroeshkin AV, Pleteneva TV, Uspenskaya EV, Levitskaya OV, Tverdislov VA. On the possibility of chiral structure density submillimeter inhomogeneities existing in water. J Water Chem Techn 2017;39:319-24.

18. Elena V Uspenskaya, Tatyana V Pleteneva, Anton V Syroeshkin, Ilaha V Kazimova, Tatyana E Elizarova, Artem I Odnovorov. Role of stable hydrogen isotope variations in water for drug dissolution managing. Curr Issues Pharm Med Sci 2020;33:94-101.

19. Zrelov OYu, Syroeshkin AV, Uspenskaya EV, Titorovich (Levitskaya) OV. Effect of water isotopic composition on galactose mutarotation kinetics. Pharm Chem J 2015;49:413-6.

20. Anton Syroeshkin, Maria Makarova, Tatiana Maksimova, Tatiana Pleteneva, Igor Zlatskiy. Development of zinc-enriched medicinal and food plants. SRP 2020;11:726-31.

21. Halenova T, Zlatskiy I, Syroeshkin A, Maximova T, Pleteneva T. Deuterium-depleted water as adjuvant therapeutic agent for treatment of diet-induced obesity in rats. Molecules 2020;25:23.

22. Basov A, Fedulova L, Vasilevskaya E, Dzhimak S. Possible mechanisms of biological effects observed in living systems during $2 \mathrm{H} / 1 \mathrm{H}$ isotope fractionation and deuterium interactions with other biogenic isotopes. Molecules 2019;24:4101.
23. Cisanova ES, Syroeshkin AV, Uspenskaya EV, Ul'yantsev AS, Pleteneva TV, Klimova EV, et al. The study of biological activity and the ratio of deuterium/protium $(\mathrm{D} / \mathrm{H})$ in water using a cellular biosensor S. ambiguum. Studied Russia 2010;46:558-93.

24. Lewis GN. Biology of heavy water. Nature 1934;133:620.

25. Lobyshev VN, Kalinichenko LP. Isotopic effects in biological systems. Moscow: Nauka; 1978.

26. Boros LG, D'Agostino DP, Katz HE. Submolecular regulation of cell transformation by deuterium depleting water exchange reactions in the tricarboxylic acid substrate cycle. Med Hypotheses 2016;87:69-74.

27. Robins RJ, Remaud GS, Billault I. Natural mechanisms by which deuterium depletion occurs in specific positions in metabolites. Eur Chem Bull 2012;1:39-40.

28. Cleland WW. The use of isotope effects to determine enzyme mechanisms. J Biol Chem 2003;278:51975-84.

29. Strekalova T, Evansa M, Chernopiatko A, Coucha Y, Costa Nunes J. Deuterium content of water increases depression susceptibility: the potential role of a serotonin-related mechanism. Behav Brain Res 2015;277:237-44.

30. Cărpinișan L, Petcu MD, Petrovici S, Chis C, Ghise A, Zehan R. The Influence of deuterium depleted water on the hematocrit and the leukocyte formula in rats intoxicated with chromium. Sci Papers: Animal Sci Biotech 2010;43:464-8.

31. Olariu L, Petcu M, Cuna S, Scurtu M, Tulcan C, Brudiu I. The role of deuterium depleted water (ddw) administration in blood deuterium concentration in $\mathrm{Cr}$ (VI) intoxicated rats. Lucrari Stiinłifice Med Veterinara 2010;43:193-6.

32. Hang M, Huynh V, Meyer TJ. Colossal kinetic isotope effects in proton-coupled electron transfer. PNAS 2004;101:13138-41.

33. Syroeshkin AV, Antipova NV, Zlatska AV, Zlatskiy IA, Skylska $\mathrm{MD}$, Grebennikova TV, et al. The effect of the deuterium depleted water on the biological activity of the eukaryotic cells. J Trace Elem Med Biol 2018;50:629-33.

34. Zlatskiy IA, Zlatska AV, Antipova NV, Syroeshkin AV. Effect of deuterium on the morpho-functional characteristics of normal and cancer cells in vitro. Trace Elem Electrolytes 2018;35:211-4.

35. Zlatskiy IA, Zlatska AV, Antipova NV, Dolenko SA, Gordiienko IM, Gubar OS, et al. Comparative analysis of the different dyes' potential to assess human normal and cancer cell viability in vitro under different $\mathrm{D} / \mathrm{H}$ ratios in a culture medium. Sci World J 2020. https://doi.org/10.1155/2020/2373021

36. Zlatska A, Vasyliev RG, Gordiienko IM, Rodnichenko AE, Morozova MA, Vulf MA, et al. Effect of the deuterium on efficiency and type of adipogenic differentiation of human adipose-derived stem cells in vitro. Sci Rep 2020;10:5217.

37. Zlatskiy I, Pleteneva T, Skripnikov A, Grebennikova T, Maksimova T, Antipova N, et al. Dependence of biocatalysis on $\mathrm{D} / \mathrm{H}$ ratio: possible fundamental differences for high-level biological taxons. Molecules 2020;25:4173.

38. Somlyai G, Jancso G, Jakli G, Vass K, Barna B, Lakics V, et al. Naturally occurring deuterium is essential for the normal growth rate of cells. FEBS Lett 1993;317:1-4.

39. Demmig Adams B, Stewart JJ, Adams WW. Multiple feedbacks between chloroplast and whole plant in the context of plant adaptation and acclimation to the environment. Philos Trans R Soc Lond B Biol Sci 2014;369:20130244.

40. Buchachenko AL, Kuznetsov DA. Magnesium magnetic isotope effect: A key to the mechanochemistry of phosphorylating enzymes as molecular machines. Mol Biol 2006;40:9-15.

41. Maret W. The Metals in the biological periodic system of the elements: concepts and conjectures. Int J Mol Sci 2016;17:66.

42. Dzhimak SS, Basov AA, Baryshev MG. Content of deuterium in biological fluids and organs: influence of deuterium depleted water on $\mathrm{D} / \mathrm{H}$ gradient and the process of adaptation biochemistry. Bioph Mol Biol 2015;465:370-3.

43. Yavari K, Kooshesh L. Deuterium depleted water inhibits the proliferation of human MCF7 breast cancer cell lines by inducing cell cycle arrest. Nutr Cancer 2019;71:1019-29.

44. Gyongyi F, Budan I, Szabo W. Deuterium depleted water effects on survival of lung cancer patients and expression of kras, $\mathrm{Bcl} 2$, and Myc genes in mouse lung. Nutr Cancer 2013;65:240-6.

45. Tracey Pirali, Marta Serafini, Sarah Cargnin, Armando A. Genazzani applications of deuterium in medicinal chemistry. J Med Chem 2019;62:5276-97. 
46. Kovacs A, Guller I, Krempels K, Somlyai I, Janosi I, Gyöngyi Z. Deuterium depletion may delay the progression of prostate cancer. J Cancer Ther 2011;2:548-56.

47. Thulasiram HV, Phan RM, Rivera SB, Poulter CD. Synthesis of deuterium-labeled derivatives of dimethylallyl diphosphate. J Org Chem 2006;71:1739-41.

48. Sattler A. Hydrogen/Deuterium (H/D) exchange catalysis in alkanes. ACS Catal 2018;8:2296-312.

49. Belleau B, Burba J, Pindell M, Reiffenstein J. Effect of deuterium substitution in sympathomimetic amines on adrenergic responses. Science 1961;133:102-4.

50. Elison C, Rapoport H, Laursen R, Elliott HW. Effect of deuteration of $\mathrm{N}-\mathrm{CH} 3$ group on potency and enzymatic $\mathrm{N}$ demethylation of morphine. Science 1961;134:1078-9.

51. Sipes IG, Gandolfi AJ, Pohl LR, Krishna G, Brown BR Comparison of the biotransformation and hepatotoxicity of halothane and deuterated halothane. J Pharmacol Exp Ther 1980;214:716-20.

52. Claassen DO, Carroll B, De Boer LM, Wu E, Ayyagari R, Gandhi S, et al. Indirect tolerability comparison of deutetrabenazine and tetrabenazine for huntington disease. J Clin Mov Disord 2017;4:3-13.

53. Garay RP, Grossberg GT. AVP-786 for the treatment of agitation in dementia of the Alzheimer's type. Expert Opin Invest Drugs 2017;26:121-32.

54. Xie JH, Gillooly K, Zhang Y, Yang X, Zupa Fernandez A, Cheng L, et al. 349-BMS-986165 is a highly potent and selective allosteric inhibitor of TYK2, blocks IL-12, IL-23 and type I interferon signaling and provides for robust efficacy in preclinical models of systemic lupus erythematosus and inflammatory bowel disease. Gastroenterology 2018;154:S-1357.

55. Khan AJ, Misenko SM, Thandoni A, Schiff D, Jhawar SR, Bunting $\mathrm{SF}$, et al. VX-984 is a selective inhibitor of non-homologous end joining, with possible preferential activity in transformed cells. Oncotarget 2018;9:25833-41.

56. First-in-human study of the safety. Tolerability, and Pharmacokinetic/Pharmacodynamic profile of VX-984 in combination with chemotherapy. Available from: clinicaltrials. govidentifier:NCT02644278. [Last accessed on 15 Nov 2018]

57. Hearn BR, Fontaine SD, Pfaff SJ, Schneider EL, Henise J, Ashley GW, et al. Primary deuterium kinetic isotope effects prolong drug release and polymer biodegradation in a drug delivery system. J Controlled Release 2018;278:74-9.

58. Malmlof T, Rylander D, Alken RG, Schneider F, Svensson TH, Cenci MA, et al. Deuterium substitutions in the L-DOPA molecule improve its anti-akinetic potency without increasing dyskinesias. Exp Neurol 2010;225:408-15.

59. Calinski DM, Zhang H, Ludeman S, Dolan ME, Hollenberg PF. Hydroxylation and $\mathrm{N}$-dechloroethylation of ifosfamide and deuterated ifosfamide by the human cytochrome p450s and their commonly occurring polymorphisms. Drug Metab Dispos 2015;43:1084-90.

60. Bhadra PB, Hassanzadeh A, Arsic B, Allison DG, Morris GA, Barber J. Enhancement of the properties of a drug by monodeuteriation: reduction of acid-catalyzed formation of a gut-motilide enol ether from 8-deuterio-erythromycin B. Org Biomol Chem 2016;14:6289-96.

61. Shao L, Abolin C, Hewitt MC, Koch P, Varney M. Derivatives of tramadol for increased duration of effect. Bioorg Med Chem Lett 2006;16:691-4.

62. Smith SW. Chiral toxicology: It's the same thing..only different. Toxicol Sci 2009;110:4-30.

63. Csuk R. Biocatalysis in the pharma and biotech industries. CRC Press: Boca Raton FL; 2007. p. 699-716.

64. Hutt AJ, Valentova J. The chiral switch: the development of single enantiomer drugs from racemates. Acta Fac Pharm Univ Comenianae 2003;50:7-23.

65. Ali I. Homochiral drug design and development by racemization. Comb Chem High Throughput Screening 2007;10:326-35.

66. Somogyi A, Bochner F, Foster D. Inside the isomers: the tale of chiral switches. Aust Prescr 2004:27:47-9.

67. Mori $\mathrm{T}$, Ito $\mathrm{T}$, Liu S, Ando $\mathrm{H}$, Sakamoto S, Yamaguchi $\mathrm{Y}$, et al. Structural basis of thalidomide enantiomer binding to cereblon. Sci Rep 2018;8:1294-307.

68. Yamamoto T, Tokunaga E, Nakamura S, Shibata N, Toru T. Synthesis and configurational stability of (S)-and (R)deuteriothalidomides. Chem Pharm Bull 2010;58:110-2.

69. Jacques V, Czarnik AW, Judge TM, Van der Ploeg LH, DeWitt SH. Differentiation of antiinflammatory and antitumorigenic properties of stabilized enantiomers of thalidomide analogs. Proc Natl Acad Sci USA 2015;112:E1471-9.

70. Mullard A. Deuterated drugs draw heavier backing. Nat Rev Drug Discovery 2016;15:219-21.

71. Graham S Timmins. Deuterated drugs; where are we now? Expert Opin Ther Pat 2014;24:1067-75.

72. Tripathy S, Mohanty PK. Mesenchymal stem cells: an innovative approach in pharmacokinetics. Asian J Pharm Clin Res 2017;10:25-36.

73. Viswanathan B, Tks S, Chida AR, Stanly DM. Physiologicallybased pharmacokinetic model for plant-based anti-oxidant drugs. Asian J Pharm Clin Res 2016;9:223-9.

74. Pathare B, Tambe V, Patil V. A review on various analytical methods used in determination of dissociation constant. Int J Pharm Pharm Sci 2014;6:26-34.

75. Saxena A, Gupta AK, Nainar MS, Bob M, Kasibhatta R. Quantification of urapidil in human plasma using ultraperformance liquid chromatography-electrospray ionization mass spectrometry (uplc-ms/ms) for pharmacokinetic study in healthy indian volunteers. Int J Pharm Pharm Sci 2014;6:56570 . 